\title{
Gender differences in minor morbidity among full time employees of a British university
}

\author{
Carol Emslie, Kate Hunt, Sally Macintyre
}

\begin{abstract}
Study objective-To examine gender differences in minor morbidity among men and women working in similar circumstances, and to test whether the relation between reported working conditions and health is similar for men and women.

Design-Multivariate analysis of data collected from a postal questionnaire distributed to full time employees in white collar jobs within a single organisation.

Setting-A British university.

Participants-1641 employees (1009 men and 632 women) working full time in white collar occupations in the university.

Main results-Overall, female university employees reported more "physical" symptoms $(2.0 v 1.7, \mathrm{p}<0.001)$ and more "malaise" symptoms (1.4 $v 1.1, \mathrm{p}<0.001)$ than male employees, but mean scores on a measure of minor psychiatric morbidity did not differ by gender. Poor perceived working conditions (and particularly lack of job stimulation, job drain and poor physical conditions) were consistently related to all three measures of minor morbidity, and these variables accounted for most of the variance in these health measures in this sample. When the analysis controlled for occupational grade, perceived working conditions and orientation to gender roles, there was no difference between men and women for any of the health measures. The relations for the predictor variables were generally the same for men and women (and there were no interactions with gender for any of the work related variables).

Conclusions-Although small gender differences in recent experience of malaise and physical symptoms remain when examining men and women in as similar working circumstances as possible, these differences are cumulatively eroded by taking account of occupational grade, reported working conditions and orientation to gender. These results lend support to a differential exposure, rather than a differential vulnerability, model of gender differences in health.

(f Epidemiol Community Health 1999;53:465-475)
\end{abstract}

MRC Social and

Public Health Sciences

Unit, 6 Lilybank

Gardens, Glasgow

G12 8RZ

Correspondence to:

Kate Hunt.

Accepted for publication

11 February 1999
In this paper we examine gender differences studies of gender differences in health compare is well known (a) that women and men still occupy quite different positions in the labour market, and (b) that working conditions may influence current health. This prompted us to ask whether gender differences in common aspects of morbidity would remain if we took samples of women and men who were employed in as similar situations as possible given the gender segregation of the labour market. In this introduction we briefly review relevant areas of the literature. Firstly, we summarise evidence on gender differences in health; secondly we discuss gendered segregation in the formal labour market and the effects of paid work on aspects of health; and finally we illustrate the widespread tendency to presume differences between men and women rather than to empirically test whether such differences exist.

Gender differences in health

It is commonly observed that in contemporary industrialised societies women live longer than men, but have higher rates of morbidity and health service use than do men (see for example ${ }^{1-7}$ ). While recent analyses have suggested that the universal picture of women's greater morbidity might have been exaggerated for some aspects of health, ${ }^{89}$ a female excess for minor and psychological conditions has been more consistently observed. Suggested explanatory frameworks for these differences include biological factors, acquired risks relating to different exposures or behaviours, reporting differences, and different access to health care." That the "female excess of ill health is caused by the social positions they occupy in contemporary society" has been a "particularly prominent theme" (page 21). ${ }^{10}$ That is, it is argued that as social positions might themselves be directly or indirectly health promoting or health damaging, it may be their differential allocation among women and men, rather than other aspects of their gender (such as biological vulnerability, tendency to take risks, or reporting behaviour), that generates different morbidity rates for men and women.

\section{Gender and paid work}

Employment status and conditions determine occupational exposures, are the basis of many measures of social class, and are an important determinant of material conditions for the individual and the household. Hence, paid work is one social position or role that is crucial for understanding inequalities in health both within and between men and women. Conversely, both gender and socioeconomic status are important in "shaping the nature of work available to individuals" (page 120). ${ }^{11}$ Given the pervasiveness of a gendered division of 
labour (see Alvesson and Billing for a recent review $\left.{ }^{12}\right)$, the distribution of occupational and family roles differs greatly between men and women.

Fewer women than men work full time in Britain (in 1996, only $37 \%$ of women aged between 16 and 59 were in full time employment compared with $70 \%$ of men aged between 16 and 64), ${ }^{13}$ and women's occupational participation differs by parental status more than does the occupational participation of men. Although there has been a substantial increase in the number of women in paid employment and in those employed in traditionally male occupations, occupational gender segregation persists as one of the most enduring features of the labour market. ${ }^{14}{ }^{15}$ Horizontal and vertical occupational segregation of the labour market means that many women experience low paying jobs with little likelihood of advancement. Jobs tend to be gender typed as either "male" or "female" (horizontal sex segregation), although the characterisation of a particular job may change over time (see Alvesson and Billing ${ }^{12}$ for examples). In Britain, as in most of the member states of the European Union, women tend to be concentrated in a small number of sectors and occupations such as in clerical, service and sales work and the so called "semi-professions" of nursing, librarianship, teaching and social work. Women's occupational disadvantage is further compounded by vertical segregation (within male occupations, women remain at the bottom of the ladder and they are under-represented at senior levels within female occupations). ${ }^{16}$ Women earn on average two thirds of men's earnings, occupy less prestigious jobs and are often clustered at the lower end of the status scale in each category. ${ }^{17-20}$

A number of studies of both white collar and blue collar workers have shown that various job related factors (such as work related self esteem, work pressure, job satisfaction, physical working environment, degree of variety and challenge in work, decision latitude) are powerful predictors of physical and psychological morbidity, ${ }^{11-29}$ and several of these have shown that these features of the work environment may explain more variance in morbidity than whether the subject is male or female. ${ }^{2122} 2325$

Given persisting differences between men and women in work and family roles, some recent research has focused on two competing explanations for the gender difference in psychological health:

"The differential vulnerability hypothesis suggests that although employed men and women may be exposed to similar levels of stress, differences in response to the social environment result in women experiencing the same environmental cues as more stressful. The differential exposure explanation proposes that employed women's greater distress is a result of their higher exposure to stress, relative to employed men ... Previous research has been hampered in the effort to compare these two explanations by the lack of comparability of men's and women's lives (page 265). ${ }^{29}$
Asymmetrical treatment of men and women in research on paid work and health

We have argued elsewhere that additional factors have lead to asymmetries in the treatment of men and women in research on paid work and health. Firstly, epidemiology and the sociology of gender and health inherit a legacy of polarising men and women, male and female, masculine and feminine; "The dichotomisation of gender within social science and the observation that health status does indeed vary by sex, together predispose researchers to focus on the differences between men and women" (page 25). ${ }^{30}$ A highly prevalent (although often implicit) assumption is that whether you are male or female is one of the main determinants of your health. Its pervasiveness is demonstrated by the way morbidity or mortality rates are almost always presented separately for men and women, or controlled for age and gender, although it is seldom made explicit whether this is premised on an underlying biological or social rationale, and no systematic comparisons are then made between male and female rates or their predictors. This separate presentation further reinforces assumptions that differences in health and longevity between men and women are substantial and universal, ${ }^{31}$ and inevitable.

Secondly, while for women paid work has often been conceptualised as secondary to their role in the household, men's health has been evaluated primarily in terms of their "traditional" role as breadwinners. Thus paid work has been seen as an additional role for women (with some authors conceptualising these multiple roles as beneficial to health, and others emphasising the pressures of combining roles (for example, Roxburgh ${ }^{29}$ ), instead of being understood as an indicator of status, income and class position as it is for men. ${ }^{32}{ }^{33}$ The implications for health of the actual content of the job and the working conditions under which it is performed have been less often studied for women than for men.

Conversely, few studies examine men's, as compared with women's, domestic responsibilities and their implications for health. ${ }^{33} 34$ Feldberg and Glenn summarised the tendency to take a gender segregated approach almost 20 years ago, coining the expression "job model" for men and "gender model" for women. The job model uses the paid work people do to explain employees' health and their behaviour both at work and away from work. In the gender model, characteristics of the job are ignored in favour of personal characteristics and family circumstances. ${ }^{35}$ What this separation implies is that the relation between paid work, or domestic roles, and health differs between men and women-that is, that men's and women's health has different social determinants. This implication has rarely been examined systematically (though see the studies $^{10}{ }^{33}{ }^{34}$ ).

In the main, these asymmetries are glossed over and most studies of gender and health describe men and women in the aggregate, unable to take account of major differences in 
family roles or occupational engagement and thus failing to compare like with like. The few studies that have controlled for social roles, however, find fewer differences between men and women than are found in the aggregate. Thoits observed that "men and women appear to experience equivalent levels of distress when they hold the same numbers and types of roles. When sex differences do occur, they appear to be a function of employment rather than of marriage, contrary to popular belief" (page 259). ${ }^{36}$ An analysis of gender differences in health that compared associations between aspects of paid and domestic work among men and women in the general population who worked at least 10 hours per week ${ }^{33}$ suggested that relations between paid work and health were generally similar for men and women. However, the participants were employed in a very wide range of occupations and, in a random community-based study, few occupations were sufficiently well represented to conduct analyses controlling more stringently for occupation; only two occupations (school teachers and clerks) were represented by more than 50 respondents. ${ }^{18}$

\section{Study objectives}

Here (and in a parallel study of another white collar organisation $^{34}$ ) we examine gender differences from a particular perspective, giving salience to paid employment. Thus, we have tried to "control", as far as possible, for participation in the formal labour market by studying men and women working full time for the same employer, taking account of the kinds of jobs that they have within the organisation. Thus, by design, we are studying gender differences in health in selected groups of men and (in particular) women.

In the analyses that follow, we focus on minor morbidity because we wanted to examine health problems that are common (even in an employed, and therefore relatively healthy, population) and that have been consistently shown to vary by gender. ${ }^{8}$ In particular, we compare the explanatory power of gender (male versus female) with that of grade of employment, perceived working conditions, and other aspects of gender (which we refer to here as orientation to gender roles) in explaining variation in three measures of recent health (experience of physical symptoms, experience of malaise symptoms, and scores on a psychiatric screening instrument), while controlling broadly for sociodemographic factors. We have discussed the conceptual and theoretical background in more detail in a recent report of a similar study in another white collar organisation, a British bank. ${ }^{34}{ }^{37}$ In particular we have pointed to the erosion of the distinction in social science between "sex" and "gender", 38 which was popularised in the $1970 \mathrm{~s},{ }^{39}$ whereby sex was used to refer to biological differences between men and women, assumed to be universal and unchanging, while gender was used to refer to culturally constructed notions of masculinity and femininity, argued to be highly variable. Here we use gender to distinguish between men and women, as we do not want to imply that any differences that persist when we have taken account of these other factors are necessarily attributable to biology alone.

In summary the questions we seek to answer are: firstly, are gender differences in health observable when we compare men and women who are employed in similar circumstances (full time for the same organisation, a British university); secondly, what is the relative importance of gender, occupational grade, perceived working conditions and orientation towards gender roles in explaining minor morbidity among these university employees; and thirdly, is there any evidence that the relations between these "predictors" and health are different for men and women?

\section{Methods}

SUBJECTS

Access to respondents in the university was gained after discussions about issues of confidentiality, security and questionnaire content with the director of personnel and representatives from the trades unions. The self completion questionnaire was piloted on 90 full time employees who were externally funded in academic, clerical, technical and manual jobs at the university (pilot response rate $83 \%$ ) (see Emslie $e t a l^{40}$ for further details).

For the main study, self completion questionnaires were distributed to all 2506 men and women who worked full time for the university (more than 30 hours a week) in white collar occupations. This included employees in academic, technical, and clerical occupations. The academic group was subdivided into junior and senior academic groups because of its large size and the heterogeneity of jobs held by its occupants; these ranged from temporary research assistant to tenured, professorial heads of department. The senior academic group was made up of senior lecturers, readers and professors, a few senior researchers and those in senior academic related jobs, such as senior faculty officers and senior librarians. Lecturers were split at the senior lecturer grade, as it is at this stage that employees have to compete across faculties for a limited number of posts. The group of junior academics was comprised of lecturers, those in junior academic related jobs such as subject librarians and careers officers, and a small group of research assistants. Those defined as clerical employees by the university worked as secretaries, receptionists and typists, while technical staff provided technical laboratory support for scientists and students and assisted with research and analysis.

Respondents were sent the questionnaire and up to two reminder letters between June and August 1994, resulting in an overall response rate of $67 \%$. Women in academic positions had the highest response rate $(75 \%)$, while men in clerical jobs had the lowest return $(62 \%)$, although this figure was based on just 21 respondents. Therefore, the analyses that follow are based on a total sample size of 1641 (1009 men and 632 women). The university had no record of ethnicity for its employees in the period studied. 
Table 1 Number of men and women working full time in white collar occupations in the university by broad occupational level (grade)

\begin{tabular}{lcllc}
\hline & & & Percent women at & \\
& Men $(n)$ & Women $(n)$ & each grade & Total $(n)$ \\
\hline All & 1567 & 939 & 37 & 2506 \\
Academic & 1103 & 319 & 22 & 1422 \\
Technical & 430 & 161 & 27 & 591 \\
Clerical & 34 & 459 & 93 & 493 \\
\hline
\end{tabular}

Mirroring the labour market as a whole, gender segregation was a major feature of this institution; women made up around a third $(37 \%)$ of all full time white collar employees in the university, but comprised the vast majority of full time clerical workers (93\%), while being greatly outnumbered by men in technical (27\% women), and academic jobs ( $22 \%$ women) (see table 1).

MEASURES

The measures used in this paper are identical to those used in a parallel study in another white collar organisation. ${ }^{34}$

\section{Health measures}

This paper reports on three indicators of recent minor morbidity. The first two were derived from a symptom checklist included in the British Health and Lifestyle Survey (HALS; ${ }^{41}$ ). Respondents were asked whether they had suffered from a list of 20 common symptoms in the past month. As one aim was to examine whether the relation between minor morbidity and working conditions is similar for men and women, we have not included any sex specific symptoms. Here we report on two distinct subsets of these symptoms, malaise and physical symptoms. We have conducted a similar analysis for the total symptom score but we do not present it here because of its overlap with the two subscores.

(1) The malaise symptom score is the sum of positive responses to a subset of five (difficulty sleeping, nerves, always feeling tired, difficulty concentrating, worrying over every little thing) (data were missing for $2.7 \%(n=44)$ ).

(2) The physical symptom score is the number of symptoms from a subset of 11 (hay fever, constipation, trouble with eyes, a bad back, colds and flu, trouble with feet, kidney or bladder trouble, painful joints, trouble with ears, sinus trouble or catarrh, persistent cough) (data were missing for 3.9\% $(n=64)$ ).

(3) 12 item General Health Questionnaire (GHQ-12). This is a self administered screening instrument widely used to detect minor psychiatric morbidity. ${ }^{42}$ The 12 item version has been recommended for use in employment studies and has been shown to be responsive to both gender differences and differences in occupational status. ${ }^{43}$ Here, we use the Likert method of scoring, each item being scored from 0 to 3; the overall score ranges between 0 (very good psychological health) and 36 (very poor psychological health). We present here the log of GHQ score, as the distribution on the raw GHQ score was skewed (data were missing for $0.5 \%(n=10))$.
Independent variables

The independent variables used can be grouped, following the logic of our research questions as outlined above, into five main blocks.

\section{Block 1. Gender}

Men were coded as 0 and women as 1 .

Block 2. Sociodemographic variables

Age in years.

Marital status was represented by two dummy variables that compared the noncohabiting never married and non-cohabiting formerly married, respectively, with those currently married or cohabiting.

Parental status was represented by two dummy variables, the first indicating whether respondents had ever had a child, and the second whether they currently had a child under five in the household.

Partner's occupation was included to attempt to control for household material circumstances although much of the variation in socioeconomic status has already been controlled for in the design of the survey; all respondents, by definition, were white collar workers in full time employment, and the vast majority of them possessed cars and lived in owner occupied homes. Using the Registrar General's classification of occupational social class, ${ }^{44}$ partners' occupations were dichotomised to contrast those in social classes I or II with those in lower socioeconomic occupations, those not in paid employment and those without partners.

The respondents were not asked about their ethnic group. The university is situated in one of the more ethnically homogeneous parts of Britain: the 1991 census reports that $98.4 \%$ of the general population are white for the broader region, and $96.8 \%$ for the city, in which it is based.

Block 3. Occupational grade

This variable controlled for broad position in the organisational hierarchy. Three dummy variables were entered into the analysis, comparing junior academics, technical and clerical employees, respectively, with senior academics.

Block 4. Working conditions and attitudes

Respondents rated a number of dimensions of their working environment. Data on job control were not collected. Factor analysis was used to derive two measures of psychosocial conditions and one measure of physical working conditions:

Lack of job stimulation. This score (Cronbach's $\alpha$ 0.84) was derived from responses to six variables (too routine, monotonous and repetitive, makes full use of abilities, interesting and challenging, sociable, enjoyable). The positive items were reversed, so that scores ranged from 0 (high job stimulation) to 18 (low job stimulation).

Job drain. This score (Cronbach's $\alpha$ 0.82) was derived from seven variables (set own pace (reversed), mentally tired out, full of stress, physically tired out, hectic or too fast, prevents feeling in control, bad for health), and had a range from 0 (no drain) to 21 (high drain). 
Table 2 Sociodemographic characteristics of the sample by gender and grade

\begin{tabular}{|c|c|c|c|c|c|}
\hline & \multicolumn{2}{|l|}{ Men } & \multicolumn{2}{|l|}{ Women } & \multirow[b]{2}{*}{ Significance $\neq$} \\
\hline & $\begin{array}{l}\text { mean }(S D T) \\
\text { or } \%\end{array}$ & total $(n)$ & $\begin{array}{l}\text { mean }(S D t) \\
\text { or } \%\end{array}$ & total $(n)$ & \\
\hline Mean age & mean $(\mathrm{SD})$ & & mean $(\mathrm{SD})$ & & \\
\hline All & $44.4(10.2)$ & 1001 & $39.4(11.6)$ & 624 & $\star \star \star \star$ \\
\hline Clerical & $32.7(13.8)$ & 21 & $40.3(13.0)$ & 295 & $\star$ \\
\hline Technical & $41.2(11.2)$ & 282 & $35.5(11.0)$ & 104 & $\star \star \star \star$ \\
\hline Junior academic & $40.3(9.9)$ & 229 & $37.1(9.4)$ & 137 & $\star \star$ \\
\hline Senior academic & $48.8(7.3)$ & 469 & $44.8(7.2)$ & 88 & 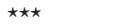 \\
\hline Mean number of years worked & mean $(\mathrm{SD})$ & & mean $(\mathrm{SD})$ & & \\
\hline All & $14.8(10.2)$ & 1006 & $10.7(9.0)$ & 628 & $\star \star \star \star$ \\
\hline Clerical & $6.3(4.4)$ & 21 & $10.8(8.4)$ & 297 & $\star$ \\
\hline Technical & $15.6(10.3)$ & 282 & $13.0(9.8)$ & 105 & $\star$ \\
\hline Junior academic & $10.5(9.8)$ & 228 & $6.4(7.3)$ & 138 & 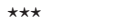 \\
\hline Senior academic & $16.8(9.8)$ & 475 & $14.2(9.6)$ & 88 & $\star$ \\
\hline Per cent married or cohabiting & $\%$ & & $\%$ & & \\
\hline All & 80 & 1007 & 56 & 631 & $\star \star \star$ \\
\hline Clerical & 38 & 21 & 53 & 298 & NS \\
\hline Technical & 76 & 284 & 55 & 106 & $\star \star \star \star$ \\
\hline Junior academic & 69 & 229 & 55 & 139 & $\star \star$ \\
\hline Senior academic & 89 & 473 & 71 & 88 & $\star \star \star$ \\
\hline Ever had children & $\%$ & & $\%$ & & \\
\hline All & 67 & 1009 & 40 & 632 & $\star \star \star$ \\
\hline Clerical & 24 & 21 & 42 & 299 & NS \\
\hline Technical & 59 & 284 & 29 & 106 & $\star \star \star$ \\
\hline Junior academic & 52 & 229 & 37 & 139 & $\star \star$ \\
\hline Senior academic & 83 & 475 & 51 & 88 & $\star \star \star \star$ \\
\hline Partner in social class I or II & $\%$ & & $\%$ & & \\
\hline All & 46 & 1009 & 35 & 632 & $\star \star \star$ \\
\hline Clerical & 5 & 21 & 22 & 299 & NS \\
\hline Technical & 32 & 284 & 32 & 106 & NS \\
\hline Junior academic & 45 & 229 & 49 & 139 & NS \\
\hline Senior academic & 57 & 475 & 58 & 88 & NS \\
\hline
\end{tabular}

†SD (continuous measures); $\ddagger t$ test for continuous measures; $\chi^{2}$ for categorical measures. ${ }^{\star} \mathrm{p}<0.05,{ }^{\star \star} \mathrm{p}<0.01,{ }^{\star \star \star} \mathrm{p}<0.001$.

Physical working conditions. This score (Cronbach's $\alpha$ 0.76) was created from seven variables (very hot, very noisy, very cold, very dusty, uncomfortably dry, poor lighting, working in a bent position) (each rated on a 5 point scale) and had a range from 0 (excellent physical conditions) to 35 (very poor conditions).

Low work ethic. Respondents were asked to what extent (5 point scale) they disagreed with three statements ("Without work a person lacks purpose in life", "As I get older work seems less important to me", "If I won or inherited a lot of money to live on I would never work again"). This score had a range from 0 to 12 (high = lowest work ethic) (Cronbach's $\alpha 0.61$ ).

Finally, two variables indicate which part of respondents' day to day life used most of their physical energy and emotional energy; in this multivariate analysis, the response "paid work" was coded as 1, and all other answers were coded as 0 .

Block 5 Orientation to gender roles

Gender role orientation. Respondents completed the 30 item Bem Sex Role Inventory, ${ }^{45}$ the most widely used and validated psychological measure of gender role orientation (see Annandale and $\mathrm{Hunt}^{30}$ for further discussion of its use in studies of health and gender). Continuous masculinity and femininity scores (each derived from the mean of 7 point ratings of the appropriateness of 10 adjectives as self descriptors, each of these adjectives being "culturally stereotypical" 45 of women or men as appropriate although no mention of gender is made in the instrument itself) were entered into the regression models. The BSRI has been validated in Scotland. ${ }^{46}$

Attitudes to traditional roles. Respondents indicated the extent of their agreement with two items from the British Social Attitudes survey ("Some equality in marriage is a good thing, but by and large the husband ought to have the main say-so in family matters" and "A husband's job is to earn the money; a wife's job is to look after the home and family"). ${ }^{47}$ These were summed to give a score with a range from 0 (strong rejection of traditional gender roles) to 8 (strong agreement with traditional gender roles) (Cronbach's $\alpha$ 0.82).

Job equality score. Respondents rated eight jobs as "equally suitable for men and women", "particularly suitable for men" or "particularly suitable for women" (see Jowell et $a l^{47}$ ). Respondents scored a point for each occupation that they did not rate as "equally suitable". The score (Cronbach's $\alpha$ 0.69) had a range from 0 (egalitarian view) to 8 .

Domestic workload. This was represented as number of minutes doing domestic chores on an average working day.

Work/home conflict. Respondents indicated the extent to which they agreed with three statements ("I sometimes feel that my work conflicts with my home life", "My job leaves me plenty of time with my family and friends", and "Working sometimes leaves me too tired to enjoy my home life"). Scores were added to create a scale (Cronbach's $\alpha$ 0.82) from 0 (no conflict) to 12 (high conflict).

The questionnaire also included questions on smoking, drinking, body mass index, and self assessments of body weight for height. We included these in a number of exploratory models but chose not to include them in the final models presented here because their inclusion made little difference to the models (for example, they did not increase the variance explained in the outcomes nor did they affect the $\beta$ values for the variables that were of 
Table 3 Reported working conditions by gender and grade

\begin{tabular}{|c|c|c|c|c|c|}
\hline & \multicolumn{2}{|l|}{ Men } & \multicolumn{2}{|l|}{ Women } & \multirow[b]{2}{*}{ Significance $\neq$} \\
\hline & $\begin{array}{l}\text { mean }(S D t) \\
\text { or } \%\end{array}$ & total $(n)$ & $\begin{array}{l}\text { mean }(S D t) \\
\text { or } \%\end{array}$ & total $(n)$ & \\
\hline \multicolumn{6}{|l|}{ Mean job drain scores } \\
\hline All & $9.7(3.9)$ & 978 & $9.2(3.7)$ & 611 & $\star \star$ \\
\hline Clerical & $8.0(4.3)$ & 21 & $8.4(3.6)$ & 286 & NS \\
\hline Technical & $7.8(3.5)$ & 279 & $8.7(3.5)$ & 102 & $\star$ \\
\hline Junior academic & $10.0(3.8)$ & 221 & $9.8(3.9)$ & 138 & NS \\
\hline Senior academic & $10.8(3.6)$ & 457 & $11.3(3.3)$ & 85 & NS \\
\hline \multicolumn{6}{|c|}{ Mean "lack of stimulation" scores } \\
\hline All & $5.6(3.2)$ & 989 & $6.4(3.6)$ & 619 & $\star \star \star$ \\
\hline Clerical & $10.3(3.6)$ & 21 & $7.3(3.5)$ & 291 & $\star \star \star$ \\
\hline Technical & $7.2(3.5)$ & 282 & $8.1(3.7)$ & 103 & $\star$ \\
\hline Junior academic & $5.3(2.6)$ & 222 & $4.9(2.7)$ & 138 & NS \\
\hline Senior academic & $4.7(2.6)$ & 464 & $3.9(2.5)$ & 87 & $\star \star$ \\
\hline \multicolumn{6}{|c|}{ Mean physical environment scores } \\
\hline All & $6.0(5.2)$ & 987 & $8.1(6.1)$ & 611 & $\star \star \star$ \\
\hline Clerical & $10.7(6.9)$ & 21 & $9.1(6.9)$ & 285 & NS \\
\hline Technical & $8.5(6.2)$ & 280 & $8.5(5.4)$ & 102 & NS \\
\hline Junior academic & $5.3(4.4)$ & 224 & $6.6(4.7)$ & 137 & $\star \star$ \\
\hline Senior academic & $4.7(4.0)$ & 462 & $6.3(4.6)$ & 87 & $\star \star \star$ \\
\hline \multicolumn{6}{|c|}{ Mean "work ethic" score } \\
\hline All & $4.7(2.6)$ & 993 & $5.1(2.5)$ & 625 & $\star \star$ \\
\hline Clerical & $4.9(3.0)$ & 21 & $5.4(2.3)$ & 296 & NS \\
\hline Technical & $5.6(2.8)$ & 282 & $5.6(2.6)$ & 105 & NS \\
\hline Junior academic & $4.3(2.4)$ & 224 & $4.6(2.5)$ & 136 & NS \\
\hline Senior academic & $4.4(2.5)$ & 446 & $4.3(2.4)$ & 88 & NS \\
\hline \multicolumn{6}{|c|}{ \% stating that "work" uses most of physical energy } \\
\hline All & 66 & 993 & 65 & 625 & NS \\
\hline Clerical & 38 & 21 & 66 & 295 & $\star$ \\
\hline Technical & 64 & 279 & 60 & 106 & NS \\
\hline Junior academic & 59 & 225 & 63 & 138 & NS \\
\hline Senior academic & 72 & 468 & 71 & 86 & NS \\
\hline \multicolumn{6}{|c|}{$\%$ stating that "work" uses most of emotional energy } \\
\hline All & 50 & $986^{\circ}$ & 43 & 621 & $\star \star$ \\
\hline Clerical & 29 & 21 & 36 & 291 & NS \\
\hline Technical & 27 & 278 & 37 & 105 & NS \\
\hline Junior academic & 57 & 224 & 49 & 139 & NS \\
\hline Senior academic & 62 & 463 & 61 & 86 & NS \\
\hline
\end{tabular}

primary interest). The context and design of the study did not allow us to explore further gender related issues, such as sexual harassment at work, sexual orientation, or domestic violence.

ANALYSIS

We used $t$ tests to test for gender differences in mean number of symptoms and mean GHQ scores and in the continuous independent variables; $\chi^{2}$ tests were used for categorical variables. Multiple regression was used to compare men and women's health after controlling for a range of variables. The five blocks of independent variables (gender, sociodemographic variables, occupational grade, working conditions and attitudes, and orientation to gender roles) were entered into the equation progressively and cumulatively; the impact of the entry of each block of variables in explaining variations in each health measure could be gauged by the change in the value of $r^{2}$.

To test for multi-collinearity, a correlation matrix for all the independent variables was obtained. Although, as expected, many of these variables were correlated, all coefficients were sufficiently low to rule out problems with multi-collinearity. Dummy variables were created in order to enter categorical variables. Generally the category suggested by the literature to be "most healthy" was used as the baseline (for example, clerical staff, technical staff and junior academics were each compared to senior academics). There were few missing data for any of the independent variables (data were missing for more than $2.0 \%$ (maximum $3.2 \%$ ) of respondents for just three of the independent variables). Cases with missing values were eliminated; the models were set up so that anyone with missing data for the any of the variables in the final model was excluded from all less complex models. To be consistent, high scores indicate poor health or poor working conditions. Thirty women who reported being pregnant within the past year were excluded from the regression analyses, as this was too small a group to analyse separately.

Interactions between gender and other independent variables were entered to test formally whether the relation between independent variables and health outcomes differed between men and women. These results are not shown in the tables, but are commented upon in the text where relevant. Further models (also not shown) included quadratic terms to check for non-linearity in the continuous measures. The addition of these terms made very little difference to the models, and had negligible effects on the variance explained by the models or on the $\beta$ values for gender.

\section{Results}

CHARACTERISTICS OF THE SAMPLE

Basic sociodemographic characteristics of the sample are presented in table 2 by gender and grade. Here we review these briefly; further details are available elsewhere. ${ }^{40}$ For the sample as a whole and in all occupational grades except the clerical grade, men and women differed significantly in the following respects. Both mean age and the length of time employed in the university were higher for men, and more men were married or cohabiting, and had children, than comparable women. The pattern by gender for each of these variables was reversed for the clerical workers, although gender differences rarely reached statistical significance given the small numbers of clerical men employed in the university. Similar proportions of men and women in technical and academic jobs had a partner working in occupations classified as social class I or II; however, this was true for fewer male clerical workers than female clerical workers.

Table 3 shows reported working conditions by gender and grade. Senior and junior academics described themselves as being most stimulated (but also most drained) by their jobs. Overall, women reported their jobs to be significantly less stimulating than men $(\mathrm{p}<0.001)$, but the gender differences varied by grade: male academics and clerical workers reported their jobs as less stimulating than equivalent women $(p<0.01$ and $p<0.001)$ while male technical workers reported their jobs as more stimulating $(\mathrm{p}<0.05)$. In the sample as a whole men reported their jobs to be more draining $(p<0.01)$, although the within occupational grade differences were mainly non-significant. However, female technical workers had a significantly higher job drain score than male technical workers. 
Table 4 Orientation to gender roles by gender and grade

\begin{tabular}{|c|c|c|c|c|c|}
\hline & \multicolumn{2}{|l|}{ Men } & \multicolumn{2}{|l|}{ Women } & \multirow[b]{2}{*}{ Significancef } \\
\hline & $\begin{array}{l}\text { mean }(S D t) \\
\text { or } \%\end{array}$ & $\begin{array}{l}\text { total } \\
(n)\end{array}$ & $\begin{array}{l}\text { mean }(S D t) \\
\text { or } \%\end{array}$ & $\begin{array}{l}\text { total } \\
(n)\end{array}$ & \\
\hline \multicolumn{6}{|c|}{ Mean BSRI "masculinity" score } \\
\hline All & $4.7(0.9)$ & 993 & $4.5(0.9)$ & 621 & $\star \star \star$ \\
\hline Clerical & $5.0(1.1)$ & 21 & $4.4(0.9)$ & 293 & $\star \star$ \\
\hline Technical & $4.6(0.9)$ & 281 & $4.4(1.0)$ & 105 & $\star$ \\
\hline Junior academics & $4.5(0.9)$ & 227 & $4.6(0.8)$ & 138 & NS \\
\hline Senior academics & $4.8(0.9)$ & 464 & $4.9(0.8)$ & 85 & NS \\
\hline \multicolumn{6}{|c|}{ Mean BSRI "femininity" score } \\
\hline All & $5.1(0.8)$ & 988 & $5.4(0.8)$ & 621 & $\star \star \star$ \\
\hline Clerical & $5.0(0.6)$ & 21 & $5.5(0.8)$ & 293 & $\star \star$ \\
\hline Technical & $5.1(0.8)$ & 280 & $5.2(0.8)$ & 105 & NS \\
\hline Junior academics & $4.9(0.9)$ & 226 & $5.2(0.7)$ & 138 & $\star \star \star$ \\
\hline Senior academics & $5.1(0.8)$ & 461 & $5.3(0.8)$ & 85 & NS \\
\hline \multicolumn{6}{|c|}{ Mean "job equality" scores } \\
\hline All & $1.7(1.7)$ & 997 & $1.4(1.6)$ & 628 & $\star \star \star \star$ \\
\hline Clerical & $1.5(1.7)$ & 21 & $1.8(1.8)$ & 296 & NS \\
\hline Technical & $2.0(1.7)$ & 283 & $1.3(1.5)$ & 106 & $\star \star \star$ \\
\hline Junior academic & $1.6(1.7)$ & 227 & $0.8(1.2)$ & 139 & $\star \star \star$ \\
\hline Senior academic & $1.6(1.7)$ & 466 & $1.4(1.7)$ & 87 & NS \\
\hline \multicolumn{6}{|c|}{ Mean no of minutes spent on domestic work on working days } \\
\hline All & $66(50)$ & 982 & $92(58)$ & 619 & $\star \star \star$ \\
\hline Clerical & $48(31)$ & 21 & $94(58)$ & 291 & $\star \star \star$ \\
\hline Technical & $74(50)$ & 279 & $94(94)$ & 104 & $\star \star$ \\
\hline Junior academic & $70(47)$ & 220 & $88(58)$ & 138 & $\star \star$ \\
\hline Senior academic & $60(50)$ & 462 & $89(54)$ & 86 & $\star \star \star \star$ \\
\hline \multicolumn{6}{|c|}{ Mean "work/home" conflict score } \\
\hline All & $6.8(3.0)$ & 994 & $5.9(2.8)$ & 626 & $\star \star \star$ \\
\hline Clerical & $3.9(2.8)$ & 21 & $4.7(2.5)$ & 294 & NS \\
\hline Technical & $4.7(2.4)$ & 282 & $5.6(2.7)$ & 105 & $\star \star$ \\
\hline Junior academic & $7.2(2.9)$ & 225 & $7.2(2.7)$ & 139 & NS \\
\hline Senior academic & $8.0(2.5)$ & 466 & $7.9(2.4)$ & 88 & NS \\
\hline
\end{tabular}

†SD (continuous measures); $\ddagger t$ test for continuous measures; $\chi^{2}$ for categorical measures. ${ }^{\star} \mathrm{p}<0.05$, ${ }^{\star \star} \mathrm{p}<0.01,{ }^{\star \star \star} \mathrm{p}<0.001$.

Table 5 Mean number of physical symptoms, malaise symptoms, and mean GHQ scores, by gender

\begin{tabular}{|c|c|c|c|c|c|}
\hline & \multicolumn{2}{|l|}{ Men } & \multicolumn{2}{|l|}{ Women } & \multirow{2}{*}{$\begin{array}{l}\text { Significance } \\
\text { (t test) }\end{array}$} \\
\hline & mean (SD) & number & mean (SD) & number & \\
\hline Physical symptoms & $1.7(1.5)$ & 972 & $2.0(1.8)$ & 576 & $\star \star \star$ \\
\hline Malaise symptoms & $1.1(1.3)$ & 981 & $1.4(1.4)$ & 587 & $\star \star \star$ \\
\hline GHQ score & $11.4(5.0)$ & 1003 & $11.3(5.2)$ & 598 & NS \\
\hline
\end{tabular}

Reported physical working conditions were poorer for clerical and technical workers than for academic employees. Overall, and among both junior and senior academics, women reported significantly poorer physical working conditions than men. The mean "work ethic" score did not vary greatly by either gender or grade (although it was somewhat lower among technical employees and female clerical workers than among academics, resulting in a significantly lower score among women as a whole). Most men and women in each grade (except clerical women) indicated that paid work was the most physically draining part of their day and there were no significant gender differences in this. Around half of the sample also indicated that paid work used most of their emotional energy. The proportion stating that paid work used most of their physical and emotional energy was highest for the senior academics, although this varied more between grades among men than among women. There were very few differences within occupational grades by gender.

More differences were apparent between men and women in the variables related to orientation to gender roles (table 4). Overall, and in the lower occupational grades, men had higher "masculinity" scores than women, but there were no differences among the two academic groups. Women had higher "femininity" scores in all grades, but the small differences were non-significant among technical and senior academics. The gender differences in both of these scores were less in this sample (in full time employment) than in general population samples (see, for example Annandale and $\mathrm{Hunt}^{30}$ ). Women were more egalitarian about "appropriate" jobs for men and women than men within the sample, but both men and women were much less traditional in their attitudes than those surveyed in the 1991 BSA survey. ${ }^{47}$ Overall, and in each grade, women reported spending significantly more time in domestic work on working days than men. Conflict between home and work was greater among academics than among clerical and technical workers. Overall men reported significantly more conflict between home and work, largely because of the high rates of home/work conflict reported by those in academic jobs (although there was no difference in the level of conflict between the two domains reported by male and female academics).

EXAMINING GENDER DIFFERENCES IN HEALTH Table 5 shows the mean values for the health measures by gender (without controlling for any independent variables). As a group, women reported significantly more physical symptoms $(2.0 v 1.7, \mathrm{p}<0.001)$ and more malaise symptoms $(1.4 v 1.1, \mathrm{p}<0.001)$ than men, but mean GHQ score did not differ by gender.

Tables 6 to 8 show the results of a series of multiple regression models for physical symptoms, malaise symptoms and GHQ score respectively. In each case a series of cumulative models is presented entering: (1) gender alone; (2) gender and sociodemographic variables; (3) gender, sociodemographic and occupational grade; (4) gender, sociodemographic, occupational grade and working conditions; (5) gender, sociodemographic, grade, working conditions and orientation to gender roles.

Firstly, although physical (table 6) and malaise (table 7) symptom scores are higher for women than for men as a whole, gender alone explains $1 \%$ or less of the variance in the three health measures examined in this sample.

Secondly, when controlling only for age and sociodemographic variables, senior academics do not differ significantly from those at other grades for malaise (table 7) or GHQ score (table 8) (although grade does become significant when other factors are subsequently included in the model); all the other occupational grades report slightly higher physical symptom scores than the senior academics (table 6). The addition of occupational grade (column 3 in tables 6 to 8) only minimally increases the variance explained. However, the gender difference in physical and malaise symptoms is attenuated and no longer significant when occupational grade and the sociodemographic variables are included (the $\beta$ value for gender remains non-significant for GHQ score).

Thirdly, it is the inclusion of the reported working conditions that has the most marked 
Table 6 Results of a series of multiple regression models for physical symptoms (standardised regression coefficients and $r^{2}$ statistics)

\begin{tabular}{|c|c|c|c|c|c|}
\hline Independent variables $(n=1390)$ & (1) Gender & $\begin{array}{l}\text { (2) } 1+ \\
\text { sociodemographic }\end{array}$ & $\begin{array}{l}\text { (3) } 2+ \\
\text { grade }\end{array}$ & $\begin{array}{l}\text { (4) } 3+\text { work } \\
\text { conditions }\end{array}$ & $\begin{array}{l}\text { (5) } 4+ \\
\text { gender roles }\end{array}$ \\
\hline Gender & $0.09^{\star \star \star}$ & $0.08^{\star \star}$ & 0.05 & 0.03 & 0.01 \\
\hline \multicolumn{6}{|l|}{ Sociodemographic } \\
\hline age & & 0.00 & 0.02 & 0.02 & 0.02 \\
\hline never married & & 0.01 & 0.02 & 0.01 & 0.01 \\
\hline formerly married & & 0.04 & 0.04 & 0.03 & 0.02 \\
\hline child under 5 at home now & & 0.01 & 0.01 & 0.00 & -0.02 \\
\hline ever had child & & -0.02 & -0.01 & 0.00 & -0.01 \\
\hline partner in social class I or II & & -0.03 & -0.01 & -0.01 & -0.02 \\
\hline \multicolumn{6}{|l|}{ Occupational grade } \\
\hline junior academic & & & $0.08^{\star}$ & $0.10^{\star \star}$ & $0.09^{\star \star}$ \\
\hline technical & & & $0.10^{\star \star}$ & $0.08^{\star}$ & $0.11^{\star \star}$ \\
\hline clerical & & & $0.10^{\star \star}$ & $0.09^{\star}$ & $0.12^{\star \star}$ \\
\hline \multicolumn{6}{|l|}{ Working conditions } \\
\hline lack of job stimulation & & & & $0.07^{\star}$ & $0.06^{\star}$ \\
\hline job drain & & & & $0.20^{\star \star \star}$ & $0.12^{\star \star}$ \\
\hline physical conditions at work & & & & $0.18^{\star \star \star}$ & $0.18^{\star \star \star}$ \\
\hline low work ethic & & & & 0.00 & 0.00 \\
\hline work uses physical energy & & & & 0.05 & 0.05 \\
\hline work uses emotional energy & & & & -0.03 & -0.03 \\
\hline \multicolumn{6}{|l|}{ Orientation to gender roles } \\
\hline BSRI masculinity score & & & & & 0.00 \\
\hline BSRI femininity score & & & & & -0.03 \\
\hline work/home conflict & & & & & $0.14^{\star \star \star}$ \\
\hline domestic chores & & & & & $0.07^{\star \star}$ \\
\hline attitude to traditional roles & & & & & 0.01 \\
\hline job equality score & & & & & -0.03 \\
\hline$r^{2}$ & 0.01 & 0.01 & 0.02 & 0.13 & 0.14 \\
\hline
\end{tabular}

${ }^{\star} \mathrm{p}<0.05,{ }^{\star \star} \mathrm{p}<0.01,{ }^{\star \star \star} \mathrm{p}<0.001$

impact on the amount of variance explained, particularly for malaise symptoms and GHQ score. Among the perceived working conditions, lack of job stimulation, high job drain (these two showing stronger relations to the more psychological measures, GHQ and malaise symptoms) and poorer physical conditions (for the two symptom scores, but not GHQ) are most consistently associated with poorer health. The inclusion of these variables weakens the $\beta$ value for gender slightly further for the two symptom scores.

Fourthly, the addition of the final block of variables (orientation to gender roles) further increases the amount of variance explained (although the increase is modest in comparison with reported working conditions). As expected from earlier literature (see Annandale and $\operatorname{Hunt}^{30}$ ), those who have higher BSRI masculinity scores have significantly better mental health (malaise symptoms and GHQ), while BSRI femininity scores are unrelated to any of the measures. Men and women who report more conflict between work and home report significantly poorer health on all three measures. In the final model, the $\beta$ value for gender is again attenuated by the addition of the "gender role" variables, and no association with gender remains for any of the measures.

Generally, the relations seen between the predictors and the health outcomes were very similar for men and women. There were no

Table 7 Results of a series of multiple regression models for malaise symptoms (standardised regression coefficients and $r^{2}$ statistics)

\begin{tabular}{|c|c|c|c|c|c|}
\hline Independent variables $(n=1403)$ & (1) gender & $\begin{array}{l}\text { (2) } 1+ \\
\text { sociodemographic }\end{array}$ & $\begin{array}{l}\text { (3) } 2+ \\
\text { grade }\end{array}$ & $\begin{array}{l}\text { (4) } 3+\text { work } \\
\text { conditions }\end{array}$ & $\begin{array}{l}\text { (5) } 4+ \\
\text { gender roles }\end{array}$ \\
\hline Gender & $0.09^{\star \star}$ & $0.06^{\star}$ & 0.06 & 0.05 & 0.03 \\
\hline \multicolumn{6}{|l|}{ Sociodemographic } \\
\hline age & & -0.04 & -0.04 & -0.05 & $-0.06^{\star}$ \\
\hline never married & & 0.04 & 0.04 & 0.05 & 0.04 \\
\hline formerly married & & 0.05 & 0.05 & $0.05^{\star}$ & 0.05 \\
\hline child under 5 at home now & & -0.01 & -0.02 & -0.03 & -0.04 \\
\hline ever had child & & 0.00 & 0.00 & 0.01 & 0.00 \\
\hline partner in social class I or II & & 0.01 & 0.01 & 0.00 & 0.00 \\
\hline \multicolumn{6}{|l|}{ Occupational grade } \\
\hline junior academic & & & 0.06 & $0.09^{\star \star \star}$ & $0.09^{\star \star}$ \\
\hline technical & & & 0.00 & 0.06 & $0.08^{\star \star}$ \\
\hline clerical & & & 0.01 & 0.06 & $0.09^{\star}$ \\
\hline \multicolumn{6}{|l|}{ Working conditions } \\
\hline lack of job stimulation & & & & $0.15^{\star \star \star}$ & $0.14^{\star \star \star}$ \\
\hline job drain & & & & $0.48^{\star \star \star}$ & $0.39^{\star \star \star}$ \\
\hline physical conditions at work & & & & $0.07^{\star \star}$ & $0.08^{\star \star}$ \\
\hline low work ethic & & & & 0.02 & 0.02 \\
\hline work uses physical energy & & & & 0.03 & 0.02 \\
\hline work uses emotional energy & & & & -0.04 & -0.04 \\
\hline \multicolumn{6}{|l|}{ Orientation to gender roles } \\
\hline BSRI masculinity score & & & & & $-0.06^{\star}$ \\
\hline BSRI femininity score & & & & & 0.01 \\
\hline work/home conflict & & & & & $0.16^{\star \star \star}$ \\
\hline domestic chores & & & & & 0.04 \\
\hline attitude to traditional roles & & & & & 0.03 \\
\hline job equality score & & & & & -0.01 \\
\hline$r^{2}$ & 0.01 & 0.01 & 0.02 & 0.30 & 0.32 \\
\hline
\end{tabular}

${ }^{\star} \mathrm{p}<0.05,{ }^{\star \star} \mathrm{p}<0.01,{ }^{\star \star \star} \mathrm{p}<0.001$. 
Table 8 Results of a series of multiple regression models for log transformed GHQ scores (standardised regression coefficients and $r^{2}$ statistics)

\begin{tabular}{|c|c|c|c|c|c|}
\hline Independent variables $(n=1428)$ & (1) Gender & $\begin{array}{l}\text { (2) } 1+ \\
\text { sociodemographic }\end{array}$ & $\begin{array}{l}\text { (3) } 2+ \\
\text { grade }\end{array}$ & $\begin{array}{l}\text { (4) } 3+\text { work } \\
\text { conditions }\end{array}$ & $\begin{array}{l}\text { (5) } 4+ \\
\text { gender roles }\end{array}$ \\
\hline \multirow{2}{*}{\multicolumn{6}{|c|}{ Sociodemographic }} \\
\hline & & & & & \\
\hline age & & $0.08^{\star}$ & $0.08^{\star}$ & $0.07^{\star}$ & $0.07^{\star}$ \\
\hline never married & & 0.03 & 0.03 & 0.03 & 0.03 \\
\hline formerly married & & $0.06^{\star}$ & 0.06 & $0.05^{\star}$ & $0.05^{\star}$ \\
\hline child under 5 at home now & & 0.05 & 0.04 & 0.03 & 0.02 \\
\hline ever had child & & 0.01 & 0.02 & 0.03 & 0.02 \\
\hline partner in social class I or II & & 0.02 & 0.00 & -0.01 & -0.01 \\
\hline \multicolumn{6}{|l|}{ Occupational grade } \\
\hline junior academic & & & 0.05 & $0.08^{\star \star}$ & $0.07^{\star}$ \\
\hline technical & & & -0.02 & 0.01 & 0.03 \\
\hline clerical & & & -0.06 & -0.04 & -0.01 \\
\hline \multicolumn{6}{|l|}{ Working conditions } \\
\hline lack of job stimulation & & & & $0.23^{\star \star \star}$ & $0.20^{\star \star \star}$ \\
\hline job drain & & & & $0.41^{\star \star \star}$ & $0.32^{\star \star \star}$ \\
\hline physical conditions at work & & & & 0.01 & 0.03 \\
\hline low work ethic & & & & -0.01 & -0.01 \\
\hline work uses physical energy & & & & 0.04 & 0.03 \\
\hline work uses emotional energy & & & & $-0.07^{\star \star}$ & $-0.07^{\star}$ \\
\hline \multicolumn{6}{|l|}{ Orientation to gender roles } \\
\hline BSRI masculinity score & & & & & $-0.10^{\star \star \star}$ \\
\hline BSRI femininity score & & & & & 0.00 \\
\hline work/home conflict & & & & & $0.17^{\star \star \star}$ \\
\hline domestic chores & & & & & 0.01 \\
\hline attitude to traditional gender roles & & & & & 0.01 \\
\hline job equality score & & & & & 0.01 \\
\hline$r^{2}+2+r$ & 0.00 & 0.01 & 0.02 & 0.25 & 0.27 \\
\hline
\end{tabular}

${ }^{\star} \mathrm{p}<0.05,{ }^{\star \star} \mathrm{p}<0.01,{ }^{\star \star \star} \mathrm{p}<0.001$.

significant interactions between gender and any of the work related variables (occupational grade and working conditions) for any of the health measures. Just two interactions were observed (both just below conventional levels of significance, $\mathrm{p}<0.05$, and consistent with chance observations). For the malaise score there was an interaction between gender and age, and for GHQ score there was an interaction between gender and "masculinity" score.

\section{Discussion}

In this study, we deliberately privileged one gendered social role (paid work) over others and compared men and women working full time in as similar occupational positions as is realistic in a society with high gender related occupational segregation. As we note elsewhere, ${ }^{34}$ we have purposefully excluded those not in paid employment, and those who work part time, and we have concentrated on one organisation to minimise the different hours, conditions, rewards and employment sectors that men and women typically inhabit. In summary, we found: (1) small, but significant gender differences for malaise and physical symptom scores, but no difference in GHQ scores, before controlling for occupational grade, perceived working conditions and orientation to gender roles, and no differences between men and women on these measures of morbidity after controlling for these factors; (2) poor perceived working conditions (particularly lack of job stimulation, job drain and poor physical conditions) were related to all three measures of minor morbidity, and accounted for much of the variance in the health measures; and (3) the relations for the predictor variables were generally the same for men and women, lending support for a differential exposure, rather than a differential vulnerability, model.

Our findings may not be generalisable to men and women employed under different conditions (for example, working part time). Given the fact that we studied full time employees, it is perhaps not surprising that perceived working conditions were so strongly associated with minor morbidity, more so than whether employees were male or female.

The results we present here are consistent with other studies that have suggested that working conditions are associated with health in similar ways for men and women. ${ }^{33}{ }^{34} \mathrm{~A}$ Canadian study, however, found that women are more vulnerable to the negative effect of job routinisation. ${ }^{29}$ That study was unable to control for occupational sector as stringently as was possible here. However, in a study in a different white collar organisation (a bank) using the same measures and analysis as the one reported here, small gender differences remained even after controlling for the other variables. ${ }^{34}$ We think that this may be because of the different ways in which being a man or a woman affects recruitment to, and occupancy of, different positions within the two organisations. Clearly there are powerful selective forces both at entry to, and promotion within, organisations that are unlikely to be gender neutral despite equal opportunities legislation. This issue needs further exploration.

Although we think that the distinction that we have made here between gender and the other groups of variables in our analysis (sociodemographic variables, occupational grade, perceived working conditions and orientation to gender) is useful analytically, we do not see these as easily distinguishable from gender in any individual's biography. Organisations are one of the sites in which gender inequalities are created and reproduced. Acker ${ }^{48}$ has argued that even the abstract category "worker" is generally seen as "someone" who has an uninterrupted full time job, and does not need to look after personal needs or dependants. Thus, jobs such as "senior academic" and "clerical 
worker" are not gender neutral. As Cockburn ${ }^{49}$ has argued: "...men and women are locked, indeed formed, in an unequal gender order...In truth ... the societal gender order ... penetrate(s) the workplace" (page 164).

The "penetration" of the societal gender order is highlighted in other ways by this analysis. One consequence of "controlling" for one gendered role (paid work - that is, occupational sector and engagement) is that it highlights differences in other gender related roles, again emphasising different selective (and self selection) processes for men and women. Thus, while these men and women were in as similar working situations as possible, they differed markedly even on the relatively crude indicators of domestic circumstances available. In the higher occupational grades, many fewer of the women were married or had children (although this was not true for women employed in the clerical grades). Other studies have reported similar findings. In our study of bank employees, $93 \%$ of male managers were married or cohabiting and $85 \%$ had children compared with $57 \%$ and $32 \%$ of female managers respectively. ${ }^{34}$ In the Whitehall II study of British civil service employees, $89 \%$ of men but only $59 \%$ of women in the highest grade were married, ${ }^{50}$ and a study of executive officers aged between 20 and 35 years working in the British civil service found that $14 \%$ of men had children compared with $1 \%$ of women. ${ }^{51}$ Tomiak et al found similar differences between middle and senior managers in the Canadian Public Service, and suggest that "the women who have achieved a higher SES (more senior management grade) are those with fewer demands on them outside the workplace. The marital status results suggest that in order to achieve a higher SES, women may have sacrificed their family lives" (page 1594)..$^{52}$ These very consistent findings emphasise important differences in the biographies of men and women working at the same grade even within the same organisations, ${ }^{18}{ }^{53}$ indicating selective processes that are likely to be associated with health in more complex ways than can be easily "controlled for" in an analysis such as this.

There are a number of potential limitations to the study that need to be acknowledged; these are discussed in more detail elsewhere. ${ }^{34}$ Firstly, there are likely to be gender differences in the meanings, resources and stressors associated with many social roles (such as family roles, or being employed) that are not captured in the indicators used here, and there are some factors (such as ethnicity, sexual harassment at work, domestic violence or sexual orientation) that may affect experience in the workplace differentially by gender. Some limits on our aims to extend our focus on gender were imposed by the design of the study. As the data were collected via a postal questionnaire delivered to respondents in their place of employment, we were limited by the length of the questionnaire, negotiations with the personnel department and the trades unions about content, and the fact that a self completion format does not lend itself to questions about some more sensitive issues such as sexual harassment.
KEY POINTS

- Among full time employees of a British university women had slightly higher rates of malaise and physical symptoms, but not of minor psychiatric morbidity, than men.

- After taking account of occupational grade, perceived working conditions and orientation to gender roles, no gender differences remained for any of these health measures.

- Reported working conditions explained a substantial amount of the variation in the health measures, especially of psychosocial health.

- After controlling for gender, sociodemographic circumstances, grade and working conditions, those who reported more work/home conflict had significantly poorer health.

- Associations between occupational factors and health were similar for men and women.

- Observed gender differences may be better explained by differential exposure, rather than differential vulnerability, to health damaging environments.

Secondly, it could be argued that there are problems with these data because all the measures are self reported. Thus health problems (especially poor mental health) may influence the reporting of working conditions or some third factor may influence the reporting of both health outcomes and working conditions. ${ }^{54}$ Where other studies have attempted to control for "negative affectivity" or "life satisfaction" the observed associations have remained. Also, as Lennon has pointed out, "while objective measures have the advantage of not being confounded with respondents' mental health status, they can omit intraoccupational variation, which may be considerable... Subjective measures ... have the advantage of being specific to the person's job" (page 124). ${ }^{11}$

Thirdly, it could be further argued that there is the possibility of contamination between the measure of job drain and the psychological health outcomes used here, as some items in the measures overlap: the malaise symptom score includes difficulty sleeping and always feeling tired, and the GHQ includes items on losing sleep over worry and feeling constantly under strain. However, it is important to note that "job drain" is also strongly associated here with the physical symptom score.

Fourthly, we are aware of the debate over which symptoms should be classified as "physical" or "malaise" symptoms. ${ }^{8} 103355$ As Blaxter remarks... "necessarily, the distinction between symptoms of illness and symptoms of malaise is arbitrary" (page 48). ${ }^{55}$

Finally, the cross sectional design of the study means that we cannot investigate time dependent issues involving occupational "exposure" and the different health outcomes. Thus, while poor psychosocial working conditions might have an immediate effect on mental health, it 
may take much longer for unfavourable working conditions to manifest themselves in physical health problems.

Despite these caveats we may conclude that while small gender differences in recent experience of malaise and physical symptoms are observable when examining men and women in as similar working circumstances as possible, these differences are cumulatively eroded by taking account of occupational grade, reported working conditions and orientation to gender. These results lend support to a differential exposure, rather than a differential vulnerability, model of gender differences in health, that is that observed gender differences in minor morbidity are attributable more to men and women being exposed to different stressors than to men and women responding differently to the same stressors.

We would like to thank a number of people at the university, particularly the respondents who took part. We are grateful to the director of personnel and other staff members in the the director of personnel and other staff members in the personnel department, and to the union representatives who
gave useful advice on the questionnaire. We would like to thank gave useful advice on the questionnaire. We would like to thank
Pat Fisher, Lindsay Macaulay and Margaret Reilly for their Pat Fisher, Lindsay Macaulay and Margaret Reilly for their
assistance in administering the survey, and Geoff Der for statisassistance in administering the survey, and Geoff Der for statis-
tical advice. We also thank Orjan Hemstrom and anonymous tical advice. We also thank Orjan
referees for their helpful comments.

Funding: this work was funded in full by the Medical Research Council of Great Britain.

Conflicts of interest: none.

1 Gove WR. Gender differences in mental and physical illness: the effects of fixed roles and nurturant roles. Soc Sci Med the effects of fixed

2 Miles A. Women, health and medicine. Milton Keynes: Open University Press, 1991.

3 Nathanson CA. Illness and the feminine role: a theoretical review. Soc Sci Med 1975;9:57-62.

4 Verbrugge LM. Gender and health: an update on hypotheses and evidence. $\mathcal{F}$ Health Social Behav 1985;26:156-82

5 Verbrugge LM. The twain meet: empirical explanations of sex differences in health and mortality. $f$ Health Social Behav 1989;30:282-304.

6 Verbrugge LM, Wingard DL. Sex differentials in health and mortality. Women Health 1987;12:103-45.

7 Waldron I. Why do women live longer than men? Soc Sci Med 1976;10:349-62.

8 Macintyre S, Hunt K, Sweeting H. Gender differences in health: are things really as simple as they seem? Soc Sci Med health: are things

9 Kandrack M-A, Grant KR, Segall A. Gender differences in health related behaviour: some unanswered questions. Soc Sci Med 1991;32:579-90.

10 Popay J, Bartley M, Owen C. Gender inequalities in health: social position, affective disorders and minor physical morbidity. Soc Sci Med 1993;36:21-32.

11 Lennon MC. Work conditions as explanations for the relation between socioeconomic status, gender, and psychological disorders. Epidemiol Rev 1995;17:120-7.

12 Alvesson M, Billing YD. Understanding gender and organizations. London: Sage, 1997.

13 Office of National Statistics. Social trends. London: HMSO, 1997.

14 Reskin BF, Roos PA. fob queues, gender queues. Explaining women's inroads into male occupations. Philadelphia: Temple University Press, 1990.

15 Williams CL. Doing “women's work”. Men in nontraditional occupations. Newbury Park: Sage, 1993.

16 Arber S, Gilbert N. Re-assessing women's working lives: an introductory essay. In: Arber S, Gilbert N, eds. Women and introductory essay. In: Arber S, Gilbert N, eds.

17 Hibbard JH, Pope CR. Employment characteristics and health status among men and women. Women Health 1987 12:85-102.

18 Hunt K, Emslie C. Men's work, women's work? Occupational sex ratios and health. In: Orth-Gomer K, Chesney $\mathrm{M}$, Wenger $\mathrm{N}$, eds. Women, stress and heart disease. Lo Angeles: Lawrence Erlbaum Associates, 1998:87-107.

19 Lennon MC. Sex differences in distress: the impact of gender and work roles. F Health Social Behav 1987;28:290305.

20 Sorensen G, Pirie P, Folsom A, et al. Sex differences in the relationship between work and health: the Minnesota Heart Survey. F Health Social Behav 1985;26:379-94.

21 Cahill J, Landbergis PA. Job strain among post office mailhandlers. Int F Health Serv 1996;26:731-50.

22 Hurrell JJ, Smith MJ. Sources of stress among machinepaced letter-sorting operators. Machine pacing and occupational stress. London: Taylor and Francis, 1981:253-9.
23 Lindstrom K. Well-being and computer mediated work of various occupational groups in banking and insurance. 3:339-61

24 Loscocco KA, Spitze G. Working conditions, social support, and the well-being of female and male factory workers. $\mathcal{f}$ Health Social Behav 1990;31:313-27.

25 Lowe G, Northcott HC. The impact of working conditions, social roles, and personal characteristics on gender differences in distress. Work and Occupations 1988;15:5577.

26 Stansfeld S, Fuhrer R, Head J, et al. Work and psychiatric disorder in the Whitehall II Study. F Psychosom Res 1997;43:73-81.

27 Walters V, French S, Eyles J, et al. The effects of paid and unpaid work on nurses' well-being: the importance of gender. Sociology of Health and Illness 1997;19:328-47.

28 Niedhammer I, Goldberg M, Leclerc A, et al. Psychosocial work environment and cardiovascular risk factors in an occupational cohort in France. $\mathcal{f}$ Epidemiol Community occupational cohort in

29 Roxburgh S. Gender differences in work and well-being: effects of exposure and vulnerability. F Health Social Behav 1996;37:265-77.

30 Annandale E, Hunt K. Masculinity, femininity and sex: an exploration of their relative contribution to explaining gender differences in health. Sociology of Health and Illness 1990;12:24-46.

31 Macintyre S. Gender differences in longevity and health in Eastern and Western Europe. In: Platt S, Thomas H, Scott $\mathrm{S}$, et al, eds. Locating health; sociological and historical explanations. Aldershot: Avebury, 1993:57-74.

32 Arber S. Class, paid employment and family roles: making sense of structural disadvantage, gender and health status. Soc Sci Med 1991;32:425-36.

33 Hunt K, Annandale E. Just the job? Is the relationship between health and domestic and paid work genderspecific? Sociology of Health and Illness 1993;15:632-64.

34 Emslie C, Hunt K, Macintyre S. Problematising gender, work and health: the relationship between gender, occupational grade, working conditions and minor morbidity in full-time bank employees. Soc Sci Med 1999;48:33-48.

35 Feldberg R, Glenn EN. Male and female: job versus gender models in the sociology of work. Social Problems 1979;26: 524-38

36 Thoits PA. Multiple identities: examining gender and marital status differences in distress. American Sociological Review 1986;51:259-72.

37 Emslie C. Banking on good health? Gender differences in minor morbidity amongst men and women working full-time in a British bank. [PhD thesis]. Glasgow: University of Glasgow, 1997.

38 Annandale E. The sociology of health and medicine. A critical introduction. Cambridge: Polity Press, 1998.

39 Oakley A. Sex, gender and society. London: Maurice Temple Smith, 1972 .

40 Emslie C, Hunt K, Macintyre S. Gender differences in health amongst men and women working full-time in white collar jobs in a British university. Glasgow: MRC Medical Sociology Unit Working Paper no 57, 1997.

41 Cox BD, Blaxter M, Buckle ALJ, et al. The health and lifestyle survey: preliminary report. London: The Health Promotion Research Trust, 1987.

42 Goldberg DP. The detection of psychiatric illness by a questionnaire. London: Open University Press (Maudsley Monograph no 21), 1972.

43 Banks MH, Clegg CW, Jackson PR, et al. The use of the General Health Questionnaire as an indicator of mental health in occupational studies. Fournal of Occupational Health 1980;53:187-94.

44 Office of Population Censuses and Surveys. Standard occupational classification. London: HMSO, 1990.

45 Bem SL. Bem Sex-Role Inventory. Professional manual. Palo Alto, California: Consulting Psychologists Press, 1981.

46 Stroebele SA. A validation of the Bem Sex Role Inventory (BSRI) in the West of Scotland. Perception of sex stereotypes [MPH thesis]. Glasgow: University of Glasgow, 1992

47 Jowell R, Curtice J, Brook L, et al. British Social Attitudes - the 11th Report. Aldershot: Dartmouth, 1994.

48 Acker J. Hierarchies, jobs, bodies: a theory of gendered organizations. In: Lorber J, Farrell SA, eds. The social construction of gender. London: Sage Publications, 1991: 162-79.

49 Cockburn C. Men's power in organizations: "equal opportunities" intervenes. In: Hearn J, Morgan D, eds. Men, masculinities and social theory. London: Unwin Hyman, 1990:72-89.

50 Marmot MG, Davey Smith G, Stansfeld S, et al. Health inequalities among British civil servants: the Whitehall 2 inequalities among British civil ser
study. Lancet 1991;337:1387-93.

51 Jenkins R. Sex differences in minor psychiatric morbidity: a survey of a homogenous population. Soc Sci Med 1985;20: 887-99

52 Tomiak M, Gentleman JF, Jette M. Health and gender differences between middle and senior managers in the Canadian public service. Soc Sci Med 1997;45:1589-96.

53 Kanter RM. Men and women of the corporation. New York: Basic books, 1977 .

54 Stronks K, van de Mheen HD, Looman CWN, et al. Behavioural and structural factors in the explanation of socio-economic inequalities in health: an empirical analysis. Sociology of Health and Illness 1996;18:653-74.

55 Blaxter M. Health and lifestyles. London: Routledge, 1990. 